\title{
Baixa estatura e magreza em crianças e adolescentes com doença falciforme
}

\author{
Stunting and wasting in children and \\ adolescents with sickle cell disease
}

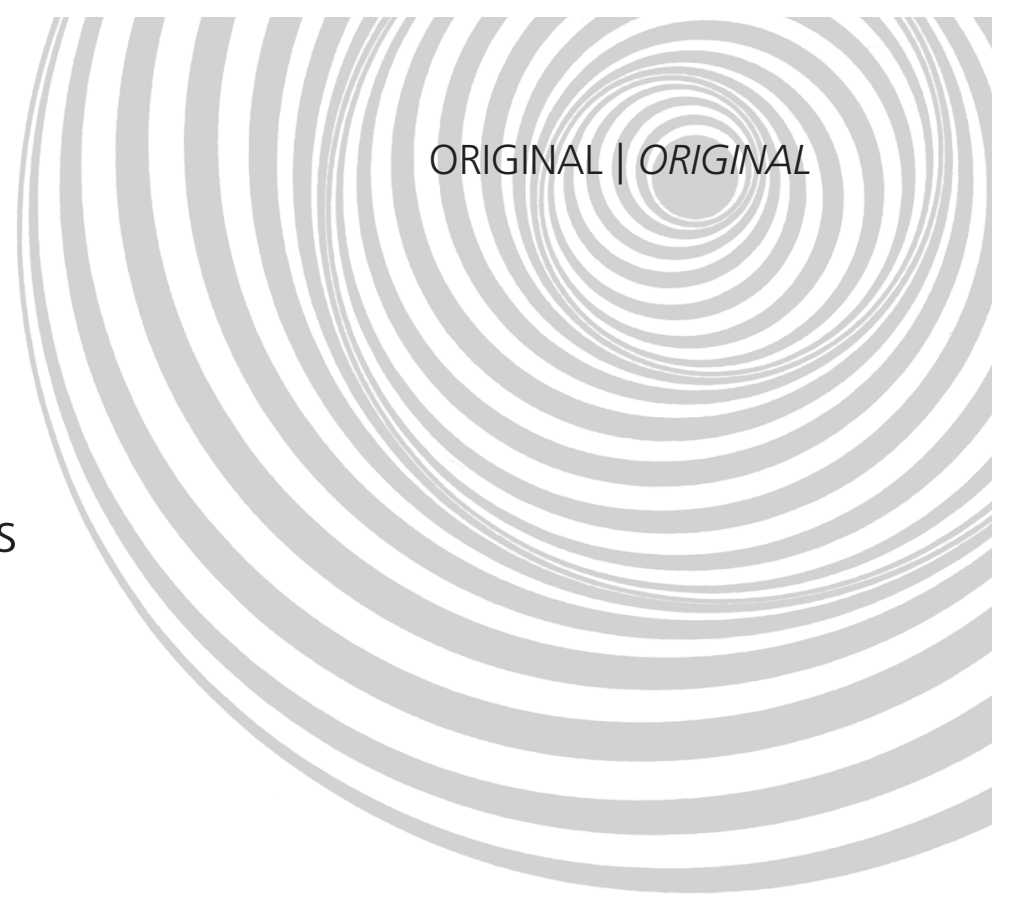

Karen Cordovil Marques de SOUZA ${ }^{1}$

Paulo Ivo Cortez de ARAÚjO2,3

Paulo Roberto Borges SOUZA-JUNIOR ${ }^{4}$

Elisa Maria de Aquino LACERDA ${ }^{5}$

RE S U M O

\section{Objetivo}

Avaliar o estado nutricional antropométrico de crianças e adolescentes com doença falciforme, atendidas em um hospital de pediatria no município do Rio de Janeiro.

\section{Métodos}

Trata-se de estudo descritivo transversal, com dados extraídos dos prontuários. Foram coletadas variáveis antropométricas, sociodemográficas, clínicas e hematológicas referentes à última consulta da criança no ano de 2006.

\section{Resultados}

A amostra foi composta por 161 crianças e adolescentes. Dentre elas, 15,5\% apresentaram baixa estatura (estatura/idade <-2 escore-Z), e 5,7\%, magreza (índice de massa corporal/idade <-2 escore-Z). Crianças de baixo peso ao nascer e cujo responsável não vive com o companheiro apresentaram menor escore-Z para o índice altura/idade do que crianças de peso adequado ao nascimento $(p=0,030)$ e cujo responsável vive com o companheiro $(p=0,003)$.

\footnotetext{
1 Especialista em Nutrição Clínica, Universidade Federal do Rio de janeiro, Instituto de Nutrição Josué de Castro, Programa de Pós-Graduação em Nutrição. Rio de Janeiro, RJ, Brasil.

2 Secretaria do Estado de Saúde e Defesa Civil do Rio de Janeiro, Programa de Atenção Integral às Pessoas com Doença Falciforme. Rio de Janeiro, RJ, Brasil.

${ }^{3}$ Universidade Federal do Rio de Janeiro, Instituto de Puericultura e Pediatria Martagão Gesteira, Centro de Referência em Assistência a Crianças com Doença Falciforme. Av. Carlos Chagas Filho, 373, Ilha do Fundão, Cidade Universitária, 21944-970, Rio de Janeiro, RJ, Brasil. Correspondência para/Correspondence to: P.I.C. ARAÚJO. E-mail:<picortez@gbl.com.br>.

${ }^{4}$ Fundação Oswaldo Cruz, Instituto de Informação e Comunicação Científica e Tecnológica. Rio de Janeiro, RJ, Brasil.

${ }^{5}$ Universidade Federal do Rio de Janeiro, Instituto de Nutrição Josué de Castro, Departamento de Nutrição e Dietética. Rio de Janeiro, RJ, Brasil.
} 
854 | K.C.M. SOUZA et al.

\section{Conclusão}

Crianças e adolescentes com doença falciforme apresentaram maior prevalência de baixa estatura e magreza em relação à população geral. Por outro lado, o baixo peso ao nascer e o fato de o responsável não viver com o companheiro foram fatores associados com a menor estatura da criança.

Termo de indexação: Adolescente. Anemia falciforme. Criança. Doença falciforme. Estado nutricional.

\section{A B S T R A C T}

\section{Objective}

This study assessed the anthropometric status of children and adolescents with sickle cell disease seen at a pediatric hospital in Rio de Janeiro county, Brazil.

\section{Methods}

This cross-sectional study collected data from medical records, which included anthropometric, sociodemographic, clinical, and hematological measurements from the last medical appointment in 2006.

\section{Results}

The study comprised 161 children and adolescents of which $15.5 \%$ were stunted (height-for-age $<-2$ Z-scores) and $5.7 \%$ were wasted (body mass index-for-age <-2 Z-scores). Children with low birth weight and those whose caregivers did not live with a partner had lower height-for-age Z-scores than children with appropriate birth weight $(p=0.030)$ and those whose caregivers lived with a partner $(p=0.003)$, respectively.

\section{Conclusion}

Children and adolescents with sickle cell disease showed a higher prevalence of stunting and wasting than the general population, and low birth weight and caregivers who did not live with a partner were associated with smaller height.

Indexing terms: Adolescent. Sickle cell anemia. Child. Sickle cell disease. Nutritional status.

\section{N T R O D U ÇÃ O}

No Brasil, há uma estimativa de que existam pelo menos dois milhões de pessoas com a hemoglobina $\mathrm{S}^{1}$. No estado do Rio de Janeiro, a incidência da doença falciforme é de um caso para 1196 nascimentos ${ }^{2}$. A doença falciforme acarreta graves manifestações clínicas, com maior frequência após os três meses de idade 3 .

No Brasil observou-se que 78,4\% dos óbitos por doença falciforme ocorrem até os 29 anos de idade, sendo que 37,5\% em menores de nove anos $^{1}$. Dentre as internações hospitalares por doen-ça falciforme ocorridas no Sistema único de Saúde no Rio de Janeiro, no período de 2000 a 2002, observou-se o percentual de $48,4 \%$ de óbitos até os 29 anos de idade, sendo 5,0\% entre 0 e 4 anos, e 6,7\% entre 5 e 9 anos $^{1}$. A mortalidade entre crianças menores de 5 anos com ane- mia falciforme 4 é secundária a infecções, sequestro esplênico e síndrome torácica aguda, tornando fundamental a existência de um cuidado especializado 5 .

Em função da anemia, da hemólise crônica e da vaso-oclusão presente, elevam-se as necessidades de proteína, energia e minerais, mesmo em períodos mais estáveis, sem crises ou complicações $^{6}$, fazendo com que pacientes com doença falciforme possuam deficiência energética relativa ${ }^{7}$. Na infância, a doença falciforme afeta a estatura e o ganho de peso já no final do primeiro ano de vida6.

A presença da desnutrição em crianças e adolescentes com anemia falciforme representa um grande impacto em sua qualidade de vida e saúde, uma vez que esse grupo já possui necessidades nutricionais aumentadas para compensar o crescimento e desenvolvimento corporal. In- 
fluenciam no deficit de crescimento e de maturação esquelética as disfunções endócrinas, o baixo consumo alimentar, os requerimentos energéticos aumentados, as baixas condições socioeconômicas ${ }^{9,10}$, a ocorrência de várias admissões hospitalares ${ }^{9}$ e a deficiência de zinco ${ }^{11}$.

A desnutrição é um componente prejudicial no prognóstico da doença falciforme. Ela acelera os processos infecciosos e de morbimortalidade na doença, sobretudo em homozigotos (SS). As crianças são vítimas potenciais devido à grande demanda energética necessária para a considerável velocidade de crescimento, ainda que decrescente e atrasada.

O estudo da composição corporal e do estado nutricional de crianças com anemia falciforme ainda é escasso no Brasil, representando uma importante lacuna no conhecimento. A investigação sobre fatores associados à desnutrição em crianças com a doença permitirá o estabelecimento de rotinas de terapêutica nutricional, proporcionando-lhes maior qualidade de vida.

O objetivo deste trabalho foi avaliar o estado nutricional antropométrico de crianças e adolescentes com doença falciforme, atendidos em um hospital pediátrico no município do Rio de Janeiro (RJ).

\section{MÉ T O D O S}

Foi realizado estudo descritivo transversal, com dados coletados a partir dos prontuários dos pacientes atendidos no Centro de Referência em Assistência a Crianças com Doença Falciforme (CRACDF) do Instituto de Puericultura e Pediatria Martagão Gesteira (IPPMG) da Universidade Federal do Rio de Janeiro (UFRJ). A amostra foi composta por todas as crianças e adolescentes atendidos no período compreendido entre janeiro e dezembro de 2006.

A captação foi feita por meio de consulta às agendas de atendimento do CRACDF no ano de 2006, tendo sido compilado o nome completo da criança, o número do prontuário e a data de consulta. Após exclusão das duplicatas, foram obtidos 214 nomes de crianças e adolescentes, cujos prontuários foram pesquisados no Serviço de Arquivo Médico do IPPMG, entre agosto e outubro de 2007, por seis entrevistadores treinados para o preenchimento do formulário de coleta de dados. Foram excluídas 53 crianças, em decorrência de diagnóstico diferente de doença falciforme $(n=29)$, traço falcêmico $(n=3)$, falta à consulta ( $n=7)$ e prontuário não localizado $(n=14)$.

As variáveis dependentes do estudo são aquelas de natureza antropométrica: peso $(\mathrm{kg}$, aferido em balança mecânica pediátrica, para crianças menores de 2 anos de idade; ou balança plataforma mecânica, para crianças com idade maior ou igual a dois anos); altura (cm, aferida em infantômetro, para crianças menores de 2 anos de idade; ou estadiômetro, para crianças com idade maior ou igual a dois anos); Índice de Massa Corporal (IMC) (obtido pela divisão do peso em quilos pelo quadrado da altura em metros); índice Peso/Altura (P/A); Índice Altura/ldade (A/I). $A$ avaliação antropométrica de crianças menores de cinco anos foi feita por meio do software WHO Anthro 2005, cujo padrão de referência é o da World Health Organization $(\mathrm{WHO})^{12}$. Para crianças entre cinco anos e dez anos utilizou-se o padrão de referência da WHO-2007 ${ }^{13}$ para os índices antropométricos peso/altura, índice de massa corporal/idade e altura/idade. Os pontos de corte adotados para deficit antropométrico foram $<-2$ e $<-3$ escores-Z (EZ), obtendo-se a seguinte classificação: baixa estatura ( $\mathrm{Al}<<-2 \mathrm{EZ}$ e $\geq 3 \mathrm{EZ}$ ), muito baixa estatura ( $\mathrm{A} / \mathrm{I}<-3 \mathrm{EZ}$ ), magreza (P/A e IMC/ idade $<-2$ EZ e $\geq 3$ EZ) e magreza acentuada (P/A e IMC/idade $<-3 \mathrm{EZ})^{14}$.

As variáveis independentes são as sociodemográficas, clínicas e hematológicas. As variáveis sociodemográficas estudadas foram: idade (anos e meses), sexo, cor da pele (não autodeclarada), situação marital do responsável (vive ou não com companheiro), condições de moradia, composição familiar e escolaridade do responsável (anos de estudo). Dados sobre renda familiar não cons- 
tavam nos prontuários dos pacientes. As variáveis clínicas pesquisadas foram: doença falciforme: SS, SC ou S $\beta$ talassemia (zero ou +), idade de início do acompanhamento e número de crises vaso-oclusivas. As variáveis hematológicas foram: série vermelha (reticulócitos ${ }^{15}$, hemoglobina ${ }^{16}$, volume globular médio ${ }^{15}$, hemoglobina globular média ${ }^{17}$, hemoglobina fetal ${ }^{18}$ ) e série branca (leucócitos ${ }^{19}$ ). Os valores de referência dos exames bioquímicos foram: Hemácias (milhões $\left./ \mathrm{mm}^{3}\right)^{15}$ - >4,5 (1 a 3 anos), >4,6 (4 a 5 anos), > 4,7 (6 a 10 anos), >4,8 (11 a 14 anos); Reticulócitos (\% $)^{15}$ - 0,5 a 1,5; Hemoglobina (g/dL) e Hematócrito ${ }^{16}$ - 11 e 33\% (6 a 59 meses), 11,5 e 34\% (5 a 11 anos), 12 e 36\% (12 a 14 anos); Hemoglobina Globular Média $(p g)^{17}$ - 22 a 30 (1 a 2 anos), 25 a 31 (3 a 8 anos), 26 a 32 (9 a 14 anos); Hemoglobina Fetal (\%) 0 a $1 \%$ (>6 meses); Leucócitos $\left(\mathrm{mm}^{3}\right)^{19}-6.000$ a 17.000 (6 meses a 2 anos), 5.500 a 15.500 (2 a 3 anos), 5.000 a 14.500 (3 a 6 anos), 5.000 a 13.000 (6 a 13 anos), 5.000 a 10.000 (>13 anos); Linfócitos $\left(\mathrm{mm}^{3}\right)^{19}$ - 3.000 a 9.500 (6 meses a 2 anos), 2.000 a 8.000 (2 a 3 anos), 1.500 a 7.000 (3 a 6 anos), 1.200 a 6.000 (6 a 13 anos), 1.000 a 5.000 (>13 anos); Volume Globular Médio $\left(\mu \mathrm{mm}^{3}\right)^{15}-78$ (1 ano), 77 (2 anos), 80 (3 a 10 anos), 82 (12 a 14 anos). Dados sobre hemotransfusão não estavam disponíveis.

As variáveis contínuas foram apresentadas na forma de medidas de tendência central (média) e dispersão (desvio-padrão), tendo sido calculadas as frequências das variáveis categóricas. Por se tratar de amostra não paramétrica, as médias dos índices antropométricos segundo variáveis categóricas de interesse foram testadas pela Análise de Variância (ANOVA), utilizando-se também o Teste $\mathrm{H}$ de Kruskal-Wallis. Foi adotado o nível de significância de 5,0\%. A análise estatística foi realizada por meio do software Epilnfo 6.04 e Statistical Package for the Social Sciences (SPSS) versão 10.0.1.

O projeto foi aprovado pelo Comitê de Ética Médica do IPPMG/UFRJ, sob protocolo $n^{\circ}$ 34/2007 em setembro de 2007, e atende às Dire- trizes e Normas Regulamentadoras de Pesquisas Envolvendo Seres Humanos, Conselho Nacional de Saúde, Resolução n 196/96. Os pesquisadores assinaram um Termo de Compromisso de Utilização de Dados.

\section{RE S U L T A D O S}

A amostra foi composta por 161 crianças e adolescentes, sendo 50,3\% do sexo masculino $(n=81)$ e $49,7 \%$ do sexo feminino $(n=80)$. A variável cor da pele somente estava disponível para 38 crianças (4 brancas, 8 negras e 26 pardas). Observou-se que $27,0 \%$ viviam em família com mais de 5 pessoas ( $n=27), 54,2 \%$ possuíam 4 ou mais cômodos na residência ( $n=58), 95,7 \%$ eram servidos pela rede geral de abastecimento de água $(n=89)$ e $87,2 \%$ pela rede de escoamento sanitário $(n=82)$ (dados não apresentados).

As frequências e médias das variáveis sociodemográficas, clínicas e hematológicas são apresentadas na Tabela 1. Não foi possível caracterizar adequadamente o estado socioeconômico das crianças devido à escassez de dados, nos prontuários, sobre renda e disponibilidade de bens materiais no domicílio. A história pregressa de aleitamento materno mostra que $15,5 \%$ das crianças receberam exclusivamente leite materno até 1 mês de idade $(n=13)$ e que 32,1\% receberam leite materno exclusivo com duração entre 4 e 6 meses ( $n=27)$. Apresentaram valores de hemoglobina $(100,0 \%)$ e hematócrito $(95,8 \%)$ abaixo dos valores considerados normais para a idade.

Foram identificadas as seguintes prevalências de alteração do estado nutricional: 12,2\% de baixa estatura $(n=19), 3,3 \%$ de muita baixa estatura ( $n=4), 3,6 \%$ de magreza segundo índice P/A, 5,7\% de magreza segundo IMC/idade $(n=7)$ e $1,6 \%$ de sobrepeso $(n=2)$ (Tabela 2 ). Não foi observada diferença na distribuição de desnutrição ou sobrepeso segundo as faixas etárias (dados não apresentados). A média de escore-Z para todos os índices antropométricos foi inferior à mediana, sendo o menor escore-Z obtido para o índice altura/idade $(-0,94)$. 
Tabela 1. Frequência e média das características sociodemográficas, clínicas e hematológicas de 161 crianças e adolescentes com doença falciforme, em um hospital pediátrico no município do Rio de Janeiro (RJ), 2006.

\begin{tabular}{|c|c|c|c|c|}
\hline Variáveis & $n$ & $\%$ & Média & DP \\
\hline Idade (anos) & & & 7,45 & 3,29 \\
\hline $0-1$ & 4 & 2,5 & & \\
\hline $2-6$ & 62 & 38,5 & & \\
\hline $7-9$ & 45 & 28,0 & & \\
\hline $10-14$ & 50 & 31,0 & & \\
\hline Total & 161 & 100,0 & & \\
\hline Peso ao nascer ( $g$ ) & & & 3180 & 52,98 \\
\hline$\leq 2499$ & 6 & 7,3 & & \\
\hline $2500-4000$ & 74 & 90,2 & & \\
\hline$>4000$ & 2 & 2,4 & & \\
\hline Total & 82 & 100,0 & & \\
\hline Aleitamento materno exclusivo (meses) & & & 3,83 & 1,88 \\
\hline $0-1$ & 13 & 15,5 & & \\
\hline $2-4$ & 41 & 48,8 & & \\
\hline $4-6$ & 27 & 32,1 & & \\
\hline$>6$ & 3 & 3,6 & & \\
\hline Total & 84 & 100,0 & & \\
\hline Escolaridade do cuidador & & & & - \\
\hline Fundamental & 50 & 67,6 & & \\
\hline Médio & 22 & 29,7 & & \\
\hline Superior & 2 & 2,7 & & \\
\hline Total & 74 & 100,0 & & \\
\hline Responsável vive com companheiro & & & & - \\
\hline $\operatorname{sim}$ & 67 & 67,7 & & \\
\hline Não & 32 & 32,3 & & \\
\hline Total & 99 & 100,0 & & \\
\hline Trabalho do cuidador & & & & - \\
\hline Sim & 77 & 87,5 & & \\
\hline Não & 11 & 12,5 & & \\
\hline Total & 88 & 100,0 & & \\
\hline \multicolumn{5}{|l|}{ Tipo $(S C D)^{*}$} \\
\hline SS & 125 & 77,6 & - & \\
\hline SC & 23 & 14,3 & & \\
\hline Sßtal & 13 & 8,1 & & \\
\hline Total & 161 & 100,0 & & \\
\hline Idade de início do acompanhamento (anos) ${ }^{t}$ & & & 2,84 & 2,86 \\
\hline$<1$ & 37 & 23,1 & & \\
\hline $1-6$ & 103 & 64,4 & & \\
\hline $6-9$ & 14 & 8,75 & & \\
\hline $9-14$ & 6 & 3,75 & & \\
\hline Total & 160 & 100,0 & & \\
\hline Número de crises vaso-oclusivas/ano & & & 1,14 & 1,51 \\
\hline Nenhuma & 63 & 47,4 & & \\
\hline $1-3$ & 60 & 45,1 & & \\
\hline$>4$ & 10 & 7,5 & & \\
\hline Total & 133 & 100,0 & & \\
\hline
\end{tabular}


Tabela 1. Frequência e média das características sociodemográficas, clínicas e hematológicas de 161 crianças e adolescentes com doença falciforme, em um hospital pediátrico no município do Rio de Janeiro (RJ), 2006.

Conclusão

\begin{tabular}{|c|c|c|c|c|}
\hline Variáveis & $\mathrm{n}$ & $\%$ & Média & DP \\
\hline Hematócrito (\%) & & & 36,77 & 2,28 \\
\hline Normal & 0 & 0,0 & & \\
\hline Abaixo do VR & 119 & 100,0 & & \\
\hline Total & 119 & 100,0 & & \\
\hline Hemoglobina ( $g / d L)$ & & & 8,32 & 1,43 \\
\hline Normal & 5 & 4,2 & & \\
\hline Abaixo do VR & 114 & 95,8 & & \\
\hline Total & 119 & 100,0 & & \\
\hline Volume globular médio $\left(\mu \mathrm{mm}^{3}\right)$ & & & 98,52 & 8,29 \\
\hline Normal & 68 & 56,7 & & \\
\hline Abaixo do VR & 15 & 12,5 & & \\
\hline Acima do VR & 37 & 30,8 & & \\
\hline Total & 120 & 100,0 & & \\
\hline Hemoglobina globular média (pg) & & & 28,51 & 0,36 \\
\hline Normal & 61 & 52,6 & & \\
\hline Abaixo do VR & 25 & 21.6 & & \\
\hline Acima do VR & 30 & 25,9 & & \\
\hline Total & 116 & 100,0 & & \\
\hline Reticulócitos (\%) & & & 12,46 & 8,16 \\
\hline Normal & 3 & 2,7 & & \\
\hline Abaixo do $V R^{\S}$ & 2 & 1,8 & & \\
\hline Acima do VR & 107 & 95,5 & & \\
\hline Total & 112 & 100,0 & & \\
\hline Leucócitos $\left(\mathrm{mm}^{3}\right)$ & & & 14,75 & 8,54 \\
\hline Normal & 43 & 36,4 & & \\
\hline Acima do VR & 75 & 63,6 & & \\
\hline Total & 118 & 100,0 & & \\
\hline Hemoglobina Fetal (\%)ll & & & 10,40 & 6,07 \\
\hline Normal & 2 & 2,8 & & \\
\hline Acima do VR & 70 & 97,2 & & \\
\hline Total & 72 & 100,0 & & \\
\hline
\end{tabular}

*SCD: Sigla que engloba todos os genótipos SS, SC e Sßtal; ${ }^{\dagger}$ Primeira consulta com o hematologista do CRACDF; § Uso de hidroxiureia ou erro no exame laboratorial; II Dados de hemoglobina fetal só estavam disponíveis para Anemia Falciforme e S $\beta$ talassemia +. DP: desvio-padrão, VR: valor de referência para idade.

A Tabela 3 apresenta a média de escore-Z para cada índice antropométrico estudado segundo as variáveis de interesse. Crianças com doença falciforme e baixo peso ao nascer apresentaram menor escore- $Z$ de altura/idade do que aquelas que nasceram com peso adequado $(-1,78$ $E Z$ vs $-0,81 E Z, p=0,030)$. Crianças cujo responsável não vivia com o companheiro apresentaram menor escore- $Z$ de altura/idade do que aquelas cujo responsável vivia com companheiro $(-1,42$ $E Z$ vs $-0,64 E Z, p=0,003)$. Não foram encontradas diferenças significativas nas médias de escore- $Z$ para as variáveis clínicas e hematológicas.

\section{I S C U S S Ã O}

O presente estudo, de base hospitalar, realizado com crianças e adolescentes da área 
Tabela 2. Estado nutricional de 161 crianças e adolescentes com doença falciforme, em um hospital pediátrico no município do Rio de Janeiro (RJ), 2006.

\begin{tabular}{|c|c|c|c|c|}
\hline Variável & $\mathrm{n}$ & $\%$ & Média & $\mathrm{DP}$ \\
\hline Altura/ldade & & & $-0,94$ & 1,20 \\
\hline$<-3 E Z$ & 4 & 3,3 & & \\
\hline$\geq-3$ e $<-2$ EZ & 15 & 12,2 & & \\
\hline$\geq-2$ e $<+2$ EZ & 104 & 84,6 & & \\
\hline$\geq+2 \mathrm{EZ}$ & 0 & 0,0 & & \\
\hline Total & 123 & 100,0 & & \\
\hline Peso/Altura & & & $-0,21$ & 1,21 \\
\hline$<-3 E Z$ & 0 & 0,0 & & \\
\hline$\geq-3$ e $<-2$ EZ & 4 & 3,6 & & \\
\hline$\geq-2$ e $<+2$ EZ & 106 & 94,6 & & \\
\hline$\geq+2 \mathrm{EZ}$ & 2 & 1,8 & & \\
\hline Total & 112 & 100,0 & & \\
\hline IMC/ldade & & & $-0,20$ & 1,05 \\
\hline$<-3 E Z$ & 0 & 0,0 & & \\
\hline$\geq-3$ e $<-2$ EZ & 7 & 5,7 & & \\
\hline$\geq-2$ e $<+2$ EZ & 114 & 92,7 & & \\
\hline$\geq+2 \mathrm{EZ}$ & 2 & 1,6 & & \\
\hline Total & 123 & 100,0 & & \\
\hline
\end{tabular}

EZ: escore-Z; IMC: índice de massa corporal; DP: desvio-padrão.

urbana do Município do Rio de Janeiro, buscou caracterizar o estado nutricional de crianças atendidas no CRACDF em razão de doença falciforme. Uma vez que o agendamento nesse Centro é bimestral para crianças no primeiro ano de vida, e trimestral ou quadrimestral para as demais crianças assistidas, é provável que todas as crianças aí atendidas tenham sido incluídas no estudo. As características sobre domicílio e escolaridade, ainda que escassas, permitem afirmar que se trata de uma população de baixa renda.

Confrontando os dados de avaliação nutricional de crianças com doença falciforme com os da população geral, observou-se, no presente estudo, maior prevalência de baixa estatura e magreza em adolescentes, comparando com a Pesquisa de Orçamentos Familiares 2002-2003 $(\mathrm{POF})^{20}$, e em crianças menores de 5 anos, comparando com os dados da Pesquisa Nacional sobre Demografia e Saúde de 1996 (PNDS) ${ }^{21}$ no Rio de Janeiro. Esses achados indicam que a prevalência de deficit nutricional em crianças com doença falciforme foi maior do que na população geral.
Considerando outros estudos sobre doença falciforme, observou-se menor proporção de baixa estatura/muito baixa estatura e magreza do que Braga et al. ${ }^{8}(15,5 \%$ vs $26,0 \%$ e $3,6 \%$ vs $32,0 \%$, respectivamente. Porém esses autores utilizaram o percentil 10 como ponto de corte, que equivale a cerca de -1,29 EZ, o que superestima a prevalência do deficit nutricional. Da mesma forma, foi menor a proporção de baixa estatura, comparando com o estudo de Rodrigues et al. ${ }^{22}$ no Rio de Janeiro, que utilizaram o ponto de corte de -1 EZ (15,5\% vs 37,5\%). Maior prevalência de baixa estatura e magreza foi encontrada no presente estudo, se comparado com a pesquisa realizada em Minas Gerais por Silva \& Viana ${ }^{23}$, que utilizaram o ponto de corte de - 2 EZ para o genótipo SS $(15,5 \%$ vs $8,2 \%$ e $3,6 \%$ vs $1,4 \%$, respectivamente). Um estudo realizado no lêmen, com 102 crianças e adolescentes com doença falciforme, no qual foram utilizadas as novas referências de crescimento da WHO e os mesmos pontos de corte aqui adotados, encontrou $54,0 \%$ de baixa estatura e $35,0 \%$ de baixo peso (segundo IMC/idade), valores bem superiores ao encontrado na presente pesquisa ${ }^{24}$.

O escore-Z médio de All encontrado $(-0,94)$ foi mais baixo do que o observado nos estudos de Zemel et al. ${ }^{10}(-0,28)$, Zemel et al..$^{11}(-0,4)$, Buison et al..$^{25}(-0,46)$ e Silva \& Viana ${ }^{23}(-0,64$ em meninos e -0,54 em meninas).

As diferenças encontradas entre os estudos podem ser decorrentes dos diferentes pontos de corte para classificação antropométrica utilizados pelos autores. Os que utilizaram pontos de corte superiores ao recomendado, como - $1 \mathrm{EZ} \mathrm{ou}$ percentil 10, superestimaram a prevalência de deficit nutricional. Além disso, é possível que a frequência de outros fatores envolvidos na etiologia do deficit de crescimento, como fatores hematológicos, cardiovasculares, socioeconômicos, função endócrina e metabólica, justifique as diferenças encontradas ${ }^{26}$.

Embora alterações no crescimento e desnutrição sejam comuns em crianças com anemia falciforme, ainda se desconhece a magnitude do envolvimento dos fatores intrínsecos e extrínsecos. 
$860 \mid$ K.C.M. SOUZA et al

Tabela 3. Escore-Z médio para os índices altura/idade, peso/altura e IMC/idade, segundo variáveis de interesse em 161 crianças e adolescentes com doença falciforme, em um hospital pediátrico no município do Rio de Janeiro (RJ), 2006.

\begin{tabular}{|c|c|c|c|c|c|c|c|c|c|}
\hline \multirow[b]{2}{*}{ Variáveis } & \multicolumn{3}{|c|}{ Altura/Idade } & \multicolumn{3}{|c|}{ Peso/Altura } & \multicolumn{3}{|c|}{ IMC/Idade } \\
\hline & $M$ & DP & $P$ & M & DP & $P$ & M & DP & $P$ \\
\hline \multicolumn{10}{|l|}{ Sexo } \\
\hline Masculino & $-0,97$ & 1,38 & 0,915 & $-0,21$ & 1,33 & 0,119 & $-0,33$ & 1,31 & 0,134 \\
\hline Feminino & $-0,90$ & 1,03 & & $-0,07$ & 0,95 & & $-0,09$ & 0,76 & \\
\hline \multicolumn{10}{|c|}{ Peso ao nascer } \\
\hline$\leq 2499 \mathrm{~g}$ & $-1,78$ & 0,85 & $0,030^{*}$ & $-1,03$ & 0,80 & 0,211 & $-0,98$ & 1,01 & 0,145 \\
\hline$>2500 \mathrm{~g}$ & $-0,81$ & 0,95 & & $-0,18$ & 1,44 & & $-0,18$ & 1,19 & \\
\hline \multicolumn{10}{|l|}{ Escolaridade } \\
\hline Fundamental & $-1,01$ & 1,55 & 0,206 & $-0,08$ & 1,47 & 0,139 & $-0,32$ & 1,24 & 0,080 \\
\hline Médio & $-0,45$ & 0,77 & & 0,17 & 0,62 & & 0,07 & 0,59 & \\
\hline \multicolumn{10}{|c|}{ Vive com companheiro } \\
\hline Sim & $-0,64$ & 1,30 & $0,003^{*}$ & $-0,19$ & 1,13 & 0,110 & $-0,23$ & 1,06 & 0,953 \\
\hline Não & $-1,42$ & 1,09 & & 0,22 & 0,87 & & $-0,02$ & 1,26 & \\
\hline \multicolumn{10}{|l|}{ Tipo (SCD) } \\
\hline SS & $-1,03$ & 1,19 & 0,240 & $-0,19$ & 1,21 & 0,496 & $-0,24$ & 1,09 & 0,489 \\
\hline SC & $-0,61$ & 1,17 & & 0,04 & 1,08 & & $-0,06$ & 0,84 & \\
\hline Sßtal & $-0,63$ & 1,33 & & $-0,17$ & 0,93 & & $-0,12$ & 1,05 & \\
\hline \multicolumn{10}{|c|}{ Hemoglobina (g/\%) } \\
\hline Normal & $-0,55$ & 0,59 & 0,363 & 0,26 & 1,33 & 0,240 & 0,30 & 1,58 & 0,148 \\
\hline Abaixo & $-0,96$ & 1,24 & & $-0,08$ & 1,22 & & $-0,23$ & 1,03 & \\
\hline \multicolumn{10}{|l|}{$\operatorname{VGM}\left(\mu m m^{3}\right)$} \\
\hline Normal & $-1,06$ & 1,29 & 0,579 & 0,06 & 1,44 & 0,457 & $-0,18$ & 1,19 & 0,833 \\
\hline Abaixo & $-0,93$ & 1,08 & & $-0,47$ & 0,97 & & $-0,47$ & 0,98 & \\
\hline Alto & $-0,69$ & 1,09 & & $-0,22$ & 0,71 & & $-0,19$ & 0,77 & \\
\hline \multicolumn{10}{|l|}{$H G M(p g)$} \\
\hline Normal & $-1,08$ & 1,28 & 0,441 & $-0,01$ & 1,40 & 0,547 & $-0,23$ & 1,14 & 0,396 \\
\hline Abaixo & $-0,88$ & 1,16 & & $-0,32$ & 1,10 & & $-0,50$ & 1,00 & \\
\hline Alto & $-0,59$ & 1,10 & & 0,05 & 0,90 & & 0,02 & 0,20 & \\
\hline \multicolumn{10}{|c|}{ Reticulócitos (\%) } \\
\hline Normal & $-0,40$ & 1,98 & 0,624 & $-1,10$ & 0,00 & 0,619 & $-0,50$ & 0,85 & 0,619 \\
\hline Abaixo & $-1,55$ & 1,06 & & $-0,20$ & 0,00 & & 0,10 & 0,00 & \\
\hline Alto & $-0,91$ & 1,23 & & $-0,16$ & 0,97 & & $-0,29$ & 0,96 & \\
\hline \multicolumn{10}{|c|}{ Leucócitos $\left(\mathrm{mm}^{3}\right)$} \\
\hline Normal & $-0,81$ & 1,05 & 0,560 & $-0,12$ & 1,05 & 0,909 & $-0,33$ & 0,90 & 0,653 \\
\hline Alto & $-1,04$ & 1,29 & & $-0,02$ & 1,33 & & $-0,16$ & 1,15 & \\
\hline \multicolumn{10}{|l|}{ Hb fetal (\%) } \\
\hline Normal & $-1,80$ & 0,00 & 0,330 & 0,40 & 1,56 & 0,606 & 1,60 & 0,00 & 0,112 \\
\hline Alto & $-0,85$ & 0,17 & & $-0,02$ & 1,41 & & $-0,09$ & 0,15 & \\
\hline
\end{tabular}

DP: desvio-padrão; IMC: índice de massa corporal; SCD: doença falciforme; VCM: volume corpuscular médio; HGM: hemoglobina globular média; Hb: hemoglobina.

O consumo dietético torna-se marcadamente reduzido no período que precede as crises vaso-oclusivas e permanece em níveis subótimos durante dias ou semanas ${ }^{26}$. A elevada demanda metabólica deve-se, em grande parte, à neces- sidade de produção de eritrócitos devido à hemólise crônica, perpassando o alto trabalho cardiovascular de rápido envio de sangue com maior conteúdo de oxigênio para os órgãos, a fim de evitar hipóxia e morte tecidual ${ }^{5}$. Outrossim, 
o atraso na maturação sexual observado nesses indivíduos está relacionado com a reduzida massa corporal, mostrando que a nutrição inadequada, além do componente endócrino, tem relação com o atraso puberal ${ }^{26}$.

Crianças com baixo peso ao nascer apresentaram menor média de escore-Z para todos os índices. Não foram identificados estudos com resultados semelhantes. É sabido que o baixo peso ao nascer, decorrente da prematuridade e/ou restrição de crescimento intrauterino, é um fator de risco para o crescimento pós-natal. O presente estudo mostra que crianças com doença falciforme e baixo peso ao nascer não conseguiram recuperar o deficit de peso ocorrido no período gestacional. Considerando a necessidade de toda criança com baixo peso ao nascimento ter um acompanhamento mais frequente pelos serviços de saúde, o fato de ela apresentar doença falciforme reforça a importância desse monitoramento, especialmente no primeiro ano de vida, a fim de que receba orientações adequadas visando ao crescimento adequado ${ }^{27,28}$. Os resultados, no entanto, devem ser vistos com cautela, uma vez que a informação sobre o peso ao nascer somente estava presente em $51 \%$ dos prontuários pesquisados $(n=82)$.

O achado da menor média de escore-Z para o índice altura/idade entre crianças com doença falciforme cujo responsável não vive com o companheiro é comum em estudos sobre desnutrição infantil, como o de Carvalhaes \& Benício ${ }^{29}$, que detectaram que a ausência do companheiro quase triplicou o risco de desnutrição infantil. É provável que a presença de um casal na família represente uma estrutura familiar mais organizada e, consequentemente, um cuidado materno mais adequado. Considerando que crianças com doença falciforme apresentam mais episódios de internação do que as saudáveis, a presença de um companheiro também pode significar um apoio financeiro e psicossocial ao tratamento da criança, refletindo-se em seu estado nutricional.

Alguns fatores, usualmente relacionados com a desnutrição infantil, mostraram-se presentes em relação a crianças com doença falciforme: o baixo peso ao nascer e a não convivência de seu responsável com um companheiro. Fatores socioeconômicos e demográficos necessitam ser mais bem conhecidos, por parte dos serviços de saúde, a fim de permitir caracterização adequada desse aspecto na clientela atendida.

Uma das limitações deste estudo está relacionada à fonte de dados, o prontuário, no qual se identificou, principalmente para as variáveis socioeconômicas, uma escassez de informações. Avaliações sobre a qualidade dos prontuários de hospitais-escola têm mostrado um quadro desalentador, que necessita ser modificado a fim de evitar, dentre outros aspectos, reflexos negativos sobre as áreas de ensino e pesquisa clínica ${ }^{30}$.

Promover um crescimento saudável, embora limitado pelos mecanismos naturais da doença, é um dos objetivos da intervenção nutricional no tratamento da doença falciforme em pediatria. A manutenção do ganho de peso e do crescimento linear é um desafio na prática clínica, devido aos processos metabólicos envolvidos na fisiopatologia da doença. A realização de estudos sobre o estado nutricional bioquímico e a composição corporal de crianças com doença falciforme permitirá diagnósticos e intervenções nutricionais mais precisos.

\section{A GRADECIMENTOS}

Ao Instituto de Puericultura e Pediatria Martagão Gesteira, aos pediatras do Centro de Referência em Assistência às Crianças com Doença Falciforme e aos alunos voluntários do Instituto de Nutrição Josué de Castro.

\section{COLABORADORES}

Todos os autores participaram de todas as fases da pesquisa e redação do artigo.

\section{REFERÊ NCIAS}

1. Loureiro MM, Rozenfeld S. Epidemiologia de internações por doenças falciformes no Brasil. Rev Saúde Pública. 2005; 39(6):943-9. doi: 10.1590/ S0034-89102005000600011.

2. Lobo CLC, Bueno LM, Moura P, Ogeda LL, Castilho S, Carvalho SMF. Triagem neonatal para hemoglobinopatias no Rio de Janeiro, Brasil. Rev Panam Salud 
Pública. 2003; 1(2-3):154-9. doi: 10.1590/\$1020-4 9892003000200018.

3. Di Nuzzo DVP, Fonseca SF. Anemia falciforme e infecções. J Pediatr. 2004; 80(5):347-54. doi: 10.15 90/S0021-75572004000600004.

4. Alves AL. Estudo da mortalidade por anemia falciforme. Inf Epidemiol SUS. 1996; 5(4):45-53.

5. American Academy of Pediatrics. Committee on Genetics. Health supervision for children with sickle cell disease. Pediatrics. 2002; 109(3):526-35. doi: 10.1542/peds.109.3.526.

6. Carneiro J, Murad Y. Crescimento e desenvolvimento. In: Manual de diagnóstico e tratamento para doenças falciformes. Brasília: Agência Nacional de Vigilância Sanitária; 2002. p.77-82.

7. Singhal A, Davies P, Wierenga K JJ, Thomas $P$, Grahanis. Is there an energy deficiency in homozygous sickle cell disease? Am J Clin Nutr. 1997; 66(2):386-90.

8. Braga JAP, Kerbauy J, Fisberg M. Zinc, copper and iron and their interrelations in the growth of sickle cell patients. Arch Latin Nutr. 1995; 45(3):198-203.

9. Barden EM, Kawchak DA, Ohene-Frempong K, Stallings V, Zemel B. Body composition in children with sickle cell disease. Am J Clin Nutr. 2002; 76: 218-25.

10. Zemel BS, Kawchak DA, Fung EB, Frempong KO, Staliings VA. Effect of zinc supplementation on growth and body composition in children with sickle cell disease. Am J Clin Nutr. 2002; 75:300-7.

11. Zemel BS, Kawchak DA, Ohene-Frempong K, Schall JI, Stallings VA. Effects of delayed pubertal development, nutritional status, and disease severity on longitudinal patterns of growth failure in children with sickle cell disease. Pediatrics Res. 2007; 61(5):607-13.

12. World Health Organization. The WHO child growth standards. Geneva: WHO; 2006 [cited 2007 Jun 24]. Available from: <http://www.who.int/ childgrowth/standards $>$.

13. World Health Organization. Growth reference data for 5-19 years: WHO Reference 2007. Geneva: WHO; 2007. [cited 2007 Jun 24]. Available from: <http://www.who.int/growthref/en/>.

14. World Health Organization. Training course on child growth assessment. Version 1. Geneva: WHO; 2006 [cited 2007 Jun 24]. Available from: <http://www. who.int/childgrowth/training/Interpreting.pdf>

15. Miller O, Gonçalves RR. Laboratório para o clínico. $8^{\text {th }}$ ed. Rio de Janeiro: Atheneu; 1999.

16. World Health Organization. Iron deficiency anaemia assessment, prevention, and control: a guide for programme managers. Geneva: WHO; 2001.

17. Yip R, Johnson C, Dallman PR. Age-related changes in laboratory values used in the diagnosis of anemia and iron deficiency. Am J Clin Nutr. 1984; 39:427-36.
18. Neto GCG, Pitombeira MS. Aspectos moleculares da anemia falciforme. J Bras Patol Med Lab. 2003; 39(1):51-3.

19. Programa Nacional de Controle da Qualidade. Valores normais hemogramas. [acesso: 2007 mar. 27]. Disponível em: <http://www.pncq.org.br/ biblioteca/valores_normais_hemograma.pdf>.

20. Instituto Brasileiro de Geografia e Estatística. Pesquisa de orçamentos familiares 2002-2003: tabelas 7-13. Brasília: IBGE; 2003 [acesso 2007 mar 27]. Disponível em: <http://www.ibge.gov.br>.

21. Sociedade Civil Bem-Estar Familiar no Brasil 1996. Pesquisa Nacional de Demografia e Saúde. Rio de Janeiro: Bemfam; 1996 [acesso 2008 jan 1]. Disponível em: <http://dtr2004.saude.gov.br>.

22. Rodrigues CSC, Lamarca FP, Carvalho CNM, Oliveira $\mathrm{CL}$, Rocha FZ, Marchon VSS, et al. Avaliação antropométrica de admissão em crianças com anemia falciforme internadas na enfermaria de pediatria do hospital Universitário Pedro Ernesto. Nutr Pauta. 2005; 7/8:25-8.

23. Silva CM, Viana MB. Growth deficits in children with sickle cell disease. Arch Med Res. 2002; 33(3): 308-12. doi:10.1016/\$0188-4409(01)00360-5.

24. Al-Saqladi AW, Bin-Gadeen HA, Brabin BJ. Growth in children and adolescents with sickle cell disease in Yemen. Ann Trop Paediatr. 2010; 30(4):287-98. doi:10.1179/146532810X12858955921113.

25. Buison AM, Kawchak DA, Schall JI, OheneFrempong K, Stallings VA, Leonard MB, et al. Bone area and bone mineral content deficits in children with sickle disease. Pediatrics. 2005; 116(4):943-9. doi: 10.1542/peds.2004-2582.

26. Al-Saqladi AW, Cipolotti R, Fijnvandraat K, Brabin BJ. Growth and nutritional status of children with homozygous sickle cell disease. Ann Trop Paediatr. 2008; 28(3):165-89. doi: 10.1179/146532808X335624.

27. Brasil. Ministério da Saúde. Fundamentos técnicocientíficos e orientações práticas para o acompanhamento do crescimento e desenvolvimento Parte 1: crescimento. Brasília: MS; 2001 [acesso: 2008 jan 7]. Disponível em: <www.saude.gov.br>.

28. Puffer ES, Schatz JC, Roberts CW. Relationships between somatic growth and cognitive functioning in young children with sickle cell disease. J Pediatr Psychol. 2010; 35(8):892-304.

29. Carvalhaes MABL, Benício MHDA. Capacidade materna de cuidar e desnutrição infantil. Rev Saúde Pública. 2002; 36(2):188-97.

30. Silva FG, Tavares-Neto J. Avaliação dos prontuários médicos de hospitais de ensino do Brasil. Rev Bras Educ Med. 2007; 31(2):113-26. doi: 10.1590/S010 $0-55022007000200002$.

Recebido em: 6/7/2010

Versão final reapresentada em: 12/9/2011 Aprovado em: 21/9/2011 